\title{
TRÂNSITOS GLOBAIS E REVOLUÇÕES LOCAIS EM EN ÉTAT DE POÉSIE, DE RENÉ DEPESTRE
}

\section{GLOBAL TRANSITS AND LOCAL REVOLUTIONS IN EN ÉTAT DE POÉSIE, BY RENÉ DEPESTRE}

\author{
Thiago Pernomian* \\ Leoné Astride Barzotto*
}

\begin{abstract}
RESUMO
René Depestre é um poeta pouco propalado em terras brasílicas. O artigo tem a intenção de contribuir para difusão e conhecimento desse singular poeta haitiano, com a análise problematizada de escritos presentes no poemário En état de poésie, cujo aparecimento se deu em 1980, podendo ser considerada, portanto, uma obra já tardia no conjunto literário do autor, que iniciou na poesia em 1945. A escolha de tal obra se justifica por ser um espaço de ponderação, de retorno, de olhar para o tronco e as raízes que foram se delineando conforme o poeta passava de país em país, em uma jornada errante, fugindo de ditaduras e se envolvendo em conspirações revolucionárias. Este artigo se divide em duas partes: na primeira fala-se do desligamento do poeta de seu Haiti natal e como isso influencia sua poesia e na segunda sobre a persistência do tema da revolução dentro de sua obra.
\end{abstract}

Palavras-chave: Migrações. René Depestre. En état de poésie.

\begin{abstract}
René Depestre is not a well-known poet in Brazil. This article aims to contribute to the dissemination and knowledge of this singular Haitian writer through the analysis of his writings from his poetry book En état de poésie (1980). This book can be considered a late work in his group of writings, as he started in poetry in 1945. The choice of this book is justified because it is a place of reflection, of return, of looking at the core and the roots that were outlined according to what the poet went through in each country he passed, in a wandering journey, fleeing away from dictatorships and getting involved in revolutionary conspiracies. This article is divided in two parts, the first part is about the poet's disconnection from his homeland Haiti and how this influenced his poetry; the second is about the persistence of the theme revolution in his work.
\end{abstract}

Keywords: Migrations. René Depestre. En état de poésie.

\footnotetext{
“Mestrando em Literatura e Práticas Culturais do PPGL-UFGD. tpernomian@gmail.com.

${ }^{* *}$ Professora permanente do PPG Letras da UFGD. Bolsista CAPES de Pós-Doutorado na Universidade da Califórnia em Berkeley. leoneastridebarzotto@gmail. com.
} 


\section{Raízes e errâncias}

René Depestre nasceu em 29 de agosto de 1926 em Jacmel, cidade localizada no sul do Haiti. Sua infância pobre não foi fator de obstrução em seu gosto pela literatura, sendo que o seu primeiro contato com a mesma foi com uma forma de literatura oral bastante presente no Haiti, a chamada audience, cuja transmissão é feita no círculo familiar ou na vizinhança. Tais histórias têm um caráter fantástico e onírico, o que as assemelha ao surrealismo que o poeta esposará mais tarde, de seu contato com poetas tais como Paul Éluard, Louis Aragon, André Breton e, principalmente, Aimé Césaire. Este último, como para todos os escritores negros de língua francesa, foi um pai (nem sempre visto com bons olhos, mas numa relação às vezes quase edipiana, veja-se Édouard Glissant, por exemplo), com seu conceito de négritude e a ponta de lança no Caribe, no que diz respeito à poesia negra engajada, em seu poema Cahier d'un retour au pays natal. A relação de Depestre com Césaire, no entanto, é calma, aceitando o movimento da négritude, porém, mais tarde, apontando seus defeitos ${ }^{1}$ e tornando a uma perspectiva literária mais híbrida, possivelmente num retorno à infância das histórias orais.

O engajamento político atravessa a obra do autor de ponta a ponta, sendo evidenciado desde muito cedo. Encarcerado em seu próprio país por suas ideias militantes, ele, após sair da prisão, exila-se. Começa então sua Odisseia ainda hoje inconclusa. Indo para França, aprofunda seu conhecimento acerca da literatura, principalmente da literatura francesa, pondo-se em contato mais estreito com as ideias surrealistas e, no campo político, com o Partido Comunista.

\footnotetext{
${ }^{1}$ Ver, a esse respeito, Bonjour et adieu à la Négritude, lúcido artigo, escrito também no ano de 1980 (no qual foi publicada a coletânea de poemas analisada aqui), em que o autor se propõe a fazer uma revisão crítica da Négritude, discutindo sua relevância no momento que surgiu e a dívida para com Césaire por haver sido seu precursor, mas observando nos mesmos traços de um essencialismo para o qual não haveria futuro. Segundo as palavras de Depestre, "Os traços dos novos tipos sociais que vão substituir brancos e negros se desenham, timidamente desfigurados, nas gestações atrozes da história. Pode-se, entretanto, estar certo de uma coisa: não é o mito odiosamente homicida de "raça", mas a força e a beleza de uma solidariedade irrestrita que tem chances de unificar os povos do planeta com o odor de maré de uma nova ordem redentora da economia, da cultura e da comunicação. Logo, o fato está aí: não há negritude para amanhã. Nesta manhã, acordando antes dos galos, Caliban, o homem das boas tempestades da esperança, viu o Orfeu negro de sua juventude voltar dos infernos com uma fada sem vida nos braços..." (p. 40). Nesse artigo, o autor afirma sua tomada de posição em favor do crioulismo, movimento híbrido que valoriza as narrativas orais e possui uma ampla difusão em espaços que serviram à colonização e problematiza, verificando a interpenetração entre a cultura dita erudita e a popular, a relação entre colonizado e colonizador, tal como o faz no Peru, porém escrevendo narrativas, um Miguel Ángel Asturias.
}

Tornando à trajetória do autor, a errância se fará presente sempre. Seus envolvimentos políticos o forçam, aonde quer que vá, a se deslocar para outro lugar, não podendo restabelecer contato com seu Haiti natal, com sua Jacmel. Exemplo disso é o poema Loin de Jacmel (DÉPESTRE, 1980, p. 55).

\section{Loin de Jacmel}

Près de quarante ans nous séparent

loin de mes racines j'ai su

tous les malheurs qui t'attendaient

j'ai été malade de tous les fléaux

qui te guettaient dans l'ombre

ils étaient derrière ma porte avant

de porter la hache au bois de ta santé

Hazel et Flora ont devasté mes jardins bien

avant leur folle équipée dans ton ciel.

Mon âme s'est ensablée longtemps avant ton port

tout en courant d'espoir s'est tu en moi des lunes

avant que ta rivière eût cesse de chanter

chaque jour un facteur invisible m'apporte

les mauvaises nouvelles de la goyave

de la mangue de l'oiseau-charpentier du café

et surtout de l'homme-néant de mon coin natal

le cheval le plus desole de ma poésie

s'appelle Jacmel ${ }^{2}$.

A terra natal, como se vê, está inscrita indelevelmente no poeta, em sua memória profunda, com uma vontade de retorno que não se apaga jamais, vontade essa como uma luz que se acende e promete dias melhores. É assim que sucede dentro da obra de Depestre. Esse sentimento é fruto da diáspora - nome surgido por consequência do holocausto judeu, que se refere ao duro deslocamento de um povo de sua terra natal em direção a outro local onde se possa viver. Sobre esse conceito diz Stuart Hall (ele mesmo um migrante diaspórico) que:

Essencialmente, presume-se que a identidade cultural seja fixada no nascimento, seja parte da natureza,

\footnotetext{
${ }^{2}$ Perto de quarenta anos nos separam/ longe de minhas raízes eu soube/ todas as pragas que te espreitavam/ eu fiquei doente por todas as catástrofes/ que te espiavam na sombra/ estavam atrás de minha porta antes/ de levar o machado à floresta de tua saúde/ Hazel e Flora devastaram meus jardins bem/ antes que sua desvairada saída no teu céu./ Minha alma se afundou na areia muito tempo antes de teu porto/ uma corrente inteira de esperança se calou luas/ antes que teu rio tenha parado de cantar/ cada dia um carteiro invisível me traz/ as más novidades da goiaba/ da manga do pássaro-carpinteiro do café/ e sobretudo do homem-nada de meu recanto natal/ o cavalo mais desolado de minha poesia/ se chama Jacmel (Tradução Livre).
} 
impressa através do parentesco e da linhagem dos genes, seja constitutiva de nosso eu mais interior. É impermeável a algo tão 'mundano', secular e superficial quanto uma mudança temporária de nosso local de residência. A pobreza, o subdesenvolvimento, a falta de oportunidades - os legados do Império em toda parte - podem forçar as pessoas a migrar, o que causa espalhamento - a dispersão. Mas cada disseminação carrega consigo a promessa de retorno redentor (HALL, 2013, p. 31).

Como seria, portanto, uma identidade constituída na diáspora ou no exílio? Uma identidade eminentemente móvel é a resposta, porém na qual há determinadas constantes que surgem sempre na memória do ser humano por ela atingido, que deve efetuar frequentes traduções entre o mundo cultural presente em sua memória e o mundo cultural do lugar no qual está vivendo. Esse embate cultural jamais é tranquilo, configurando-se para os seres em diáspora muitas vezes como doloroso por motivos os mais diversos - principalmente se o lugar de origem é um lugar vítima do imperialismo, como diz Stuart Hall, pois isso gera no lugar de chegada uma estigmatização que recai sobre o migrante, seja ela social, política, religiosa ou racial. Essa estigmatização aumenta ainda mais o desejo do retorno (retorno esse dificultado por motivos políticos, como no caso do poeta em questão neste artigo), causando assim uma angústia que se retroalimenta. Sobre esse fenômeno da migrância, Figueiredo (2010, p. 28) diz que "é vivido em um duplo movimento: de um lado, a relação com o território perdido, o país natal ou o país dos ancestrais que ficou para trás; de outro lado, a relação com o país de adoção, no qual o personagem/escritor não está totalmente adaptado", o que torna a existência do imigrante dilacerada, pois é como se ele fosse puxado pelos dois braços, mas um para cada lado: um o força a ir para casa, o outro a adaptar-se.

Outro problema originado pela diáspora é o sentimento de perda de identidade experimentado pelos que por ela passam, causada pelo desligamento da terra natal, que vai progressivamente minando a memória do migrante. Hall, no entanto, argumenta que esse tipo de diáspora, conceituada como binária, não é aquela pela qual passaram e passam os povos situados no Caribe, sendo mais próprio pensá-la de outro modo.

A cultura caribenha é essencialmente impelida por uma estratégia diaspórica. Em termos antropológi- cos, suas culturas são irremediavemente "impuras". Essa impureza, tão frequentemente construída como carga e perda, é em si mesma uma condição necessária à sua modernidade. Como observou certa vez o romancista Salman Rushdie, 'o hibridismo, a impureza, a mistura, a transformação que vem de novas e inusitadas combinações dos seres humanos, culturas, ideias, políticas, filmes, canções' é 'como a novidade que entra no mundo' (HALL, 2013, p. 37-38).

À frente, é dito ainda que para as culturas caribenhas, o tipo de referencial binário não vale, diz que "aqui, o referencial nacional não é útil" (HALL, 2013, p. 38). E se pode perceber isso na poesia de Depestre, até mesmo porque o autor, ao sair de seu país, não se insere dentro de uma comunidade haitiana que sobrevive em outro país qualquer, mas vaga sempre sozinho (França, Brasil, Cuba, dentre outros países), sem se inserir em um locus, ainda que pequeno, de cultura haitiana, para ali perpetuar as tradições recebidas, embora elas permaneçam sempre em sua memória. Podemos dizer assim que o autor, mais do que um ser diaspórico, é um ser exilado, o que acontece quando se vai só e sem vontade inicial própria. Como nos diz Ana Pizarro, seu artigo "Viagem, exílio e escrita", presente no livro "O sul e os trópicos":

No exílio, a decisão de expatriar-se não é pessoal, e se a viagem implica, desde o começo, um rompimento, com o exílio este se torna terrível pela impossibilitação de um poder que faz da viagem um destino irremissível, uma aventura assinada por um começo de fatalidade, um nascimento não desejado. Um nascimento efetivamente não desejado, incerto, para o qual não sabemos se estamos preparados, e de fato saímos dele vacilantes, com as pernas bambas, tentando apalpar a escuridão. Isto porque estamos realizando uma viagem sem disposição para ela, sem abertura ao caráter positivo do estremecimento, sem aceitação de sua condição (PIZARRO, 2006, p. 46).

Além disso, diz a autora mais adiante que "vivese o exílio fundamentalmente em duas dimensões. Experimenta-se com profundidade a dimensão da memória: a memória é uma instância que envolve o nosso presente" (PIZARRO, 2006, p. 46). E a outra dimensão de que fala a autora é o futuro, no qual há o tão sonhado regresso. Podemos constatar isso claramente no poema a seguir, de um dos livros anteriores (possivelmente por causa da maior proximidade temporal que ainda o ligava à sua 
partida do país natal) de Depestre, podemos perceber um sentimento de profunda nostalgia de quem tenta recuperar algo perdido. Vejamos isso no poema Pour Haïti, presente no livro Journal d'un animal marin de 1964.

Pluie de la terre natale, tombe, tombe, tombe avec force

Sur mon coeur qui brûle

Jette ta bonne eau fraîche

Sur mon souvenir en feu! HAITI

Il y a des centaines d'années

Que j'écris ton nom sur du sable

Et la mer toujours l'efface

Et la douleur toujours l'efface

Et chaque matin de nouveau

Je l'écris sur le sable millénaire

HAÏTI

de ma patience.

Les années passent

Dans un grand silence de mer

Dans mes veines il y a encore du courage

Et de la beauté pour des milliers d'années

Mais le corps dépend de n'importe quel petit accident

Et l'ésprit n'a pas l'éternité !

HAITI

Toi et moi nous nous regardons

À travers la vitre du temps qui passe

Ton élan met un champ de mais

Sous mes sandales

De nomade déraciné ${ }^{3}$

(DEPESTRE, 2006, p. 137).

Neste poema, o sentimento da perda é flagrante desde o começo, em que o poeta sente sua terra natal arder em sua memória, pedindo que a chuva dessa mesma terra caia sobre seu coração e acalme o fogo da saudade. A tentativa de recuperá-lo (escrevendo seu nome na areia) é pungente e repetitiva, o que está também flagrantemente exposto na reiteração do nome

\footnotetext{
${ }^{3}$ Chuva da terra natal, cai, cai com força/ Sobre meu coração que queima/ Joga tua boa água fresca/ sobre minha lembrança em fogo!/ HAITI/ Há centenas de anos/ Que eu escrevo teu nome sobre a areia/ E o mar sempre o apaga/ E a dor sempre o apaga/ E cada manhã de novo/ Eu o escrevo sobre a areia milenar/ de minha paciência./ HAITI/ Os anos passam/ Em um grande silêncio de mar/ Nas minhas veias há ainda coragem/ E beleza para milhares de anos/ Mas o corpo depende de não sei qual pequeno acidente/ E o espírito não tem a eternidade!/ HAITI/ Tu e eu nos miramos/ Através do vidro do tempo que passa/ Teu impulso põe um campo de milho/ sob minhas sandálias/ de nômade desenraizado (Tradução Livre).
}

"Haiti" em letras maiúsculas, no início de cada estrofe. Nome apagado sempre pelo mar - que o distancia do lugar desejado - e pela dor. Há, como dito na terceira estrofe, coragem e beleza para esperar ainda milhares de anos, mas o corpo é frágil e não aguenta tanto e o espírito (vemos aqui o materialismo do autor) também não. Essa espera feita na memória, no entanto, é fonte de força, de um impulso que direciona o autor para o futuro, é aquilo que "põe um campo de milho sobre as suas sandálias de nômade desenraizado" e permite-lhe viver e suportar melhor o presente.

E mesmo assim o autor não está ligado, neste livro, a um Haiti de história mítica (ligado a Dessalines, a L'Ouverture, a Macandal, dentre outros homens que participaram das lutas pela independência), mas a manifestações muito mais sutis que lhe perseguem na memória para onde quer que vá, sendo concretizadas em sua poesia, que efetua essa tradução entre o lá e o aqui. Em uma análise, mesmo superficial do poema, pode-se perceber que o que liga o autor a sua terra natal não são os feitos gloriosos de Haiti - embora haja em outros poemas o forte sentimento revolucionário, possivelmente decorrente da Revolução Haitiana mas as coisas mais simples, presentes na natureza do país, ligando o autor através de uma memória física, corporal a seu lugar de origem. Pode-se observar isso pela profusão de referências e metáforas à flora, que ligam o autor ao local da infância, tais como: racines (muito cara à poesia de Depestre), bois, jardins, ensablée, rivière, goyave, mangue, oiseau-charpentier, café e cheval. Vê-se também que o destino das raízes é acompanhado com inquietação e pesar. O Haiti na época estava sob a ditadura dos Duvalier, que governaram o país durante décadas por meio de um regime de terror, que incentivava a delação e fomentava a criação de esquadrões da morte. Papa Doc ${ }^{4}$ (François Duvalier) e Baby Doc (Jean Claude Duvalier) governaram assim o país de 1957 até 1986, sendo responsáveis por diversos massacres de civis e de opositores políticos do regime. Quando Depestre fala dos fléaux, da hache au bois é possivelmente a essa catástrofe que alude, enfraquecendo, ainda mais do que já estava enfraquecida, a saúde da árvore chamada Haiti. O tom

\footnotetext{
${ }^{4}$ O nome "Papa Doc", do créole, significa "papai doutor", fazendo referência ao tratamento gentil e carinhoso com que François Duvalier atendia mesmo as pessoas mais pobres do campo, quando ainda era médico. Esse carinho, no entanto, não permaneceu depois que o médico se tornou président à vie e deu aos tonton macoutes a "segurança" do país.
} 
crítico do autor em relação ao regime dos tiranos Doc se mostra claramente no poema L'âge de Papa Doc (A idade de Papa Doc), situado em livro anterior, Poète à Cuba, de 1976. Vejamos o trecho final do poema:

"Je suis papa doc

Je suis président à vie

Je papadoquise la vie

Je suis le volcan capital

Je suis le néo-cyclone

Je suis contre la santé

Des arbres et des poètes

Je suis une force animale

Qui se nie et se devore.

Je suis ton dernier chemin

Je suis ta pluie dernière

Je suis ton papa et ton doc

Et à bout portant en pleine poésie

Je te pa pa pa pa pa pa pa pa pa!"'5

(DEPESTRE, 2006, p. 305).

Podemos notar que mesmo quando falando do tirano que lhe governava o país, Depestre utiliza metáforas naturais. Essas metáforas que fazem referência a natureza estão presentes em boa parte da poesia do autor, não apenas configurando a parte que se pode dizer boa presente no país natal, mas também aquela que o assola, como a ditadura dos Doc. As últimas sentenças (nas quais se apóiam as outras, em uma enumeração que vai progressivamente elevando o nível de violência) do poema explicitam bem o regime que François Duvalier impunha ao país, um regime de repressão e medo, no qual nenhuma manifestação espontânea tinha lugar. A onomatopéia final, que imita o som de uma arma de fogo (revolver, possivelmente), é referência a essa violência, em grande parte perpetrada pelos chamados tonton macoutes, literalmente "bichos-papões", que tratavam de eliminar toda e qualquer resistência ao regime, constituindo uma espécie de milícia legalizada (além de guarda particular do presidente) dentro do país.

Pode-se encontrar o tema da errância e do exílio associada à formação da identidade - tal como

\footnotetext{
${ }^{5}$ Eu sou papa doc/ Eu sou presidente vitalício/ Eu papadoquizo a vida/ Eu sou o vulcão capital/ Eu sou o neo-ciclone/ Eu sou contra a saúde/ Das árvores e dos poetas/ Eu sou uma força animal/ Que se nega e se devora./ Eu sou seu último caminho/ Eu sou sua chuva última/ Eu sou seu papa e teu doc/ E de muito perto em plena poesia/ Eu te pa pa pa pa pa pa pa! (Tradução Livre).
}

diria Stuart Hall - em diversos momentos da obra. É curiosa, no entanto, a associação dessa identidade aos elementos naturais, como neste poema chamado Identité:

Un homme tendre du Québec

un jour d'été, dans une forêt natale,

murmura: je suis un sapin.

Moi, loin de Jacmel, un soir d'hiver,

j'ai susurré: je suis un cocotier.

Le monde entier en nous deux

a reconnu des fils jumeaux de sa beauté ${ }^{6}$

(DEPESTRE, 1980, p. 59).

Essa associação da identidade às árvores, bem como a referência a outros elementos naturais presentes no poema precedente, mostra algo bastante enraizado na memória do poeta, isto é, algo como a memória proustiana ${ }^{7}$, que recupera o passado por meio dos sentidos. O mar, o vento, a luz, tudo isso constitui a pátria do poeta e forja sua identidade, que não é a emotividade negra meramente, tal como pretendia Senghor, mas a de um homem transracial, que se identifica através do deslocamento e do apego à natureza, tal como se pode perceber neste outro poema:

\section{Profession de foi transraciale}

Les temples les partis les utopies et les raisons 'État ont cesse à jamais de m'émouvoir. Au quatrième top il fera exactement minuit au cadran lumineux de mes rêves. Où est la saison qui promettait à ce monde des arbres d'espoir de fraîcheur et de beauté? Au quatrième top je mettrai tous mes ismes à l'heure d'un rendez-vous au coeur de moi-même où nul être n'est une île à l'eau de ma tendresse. Mon tour de ciel est ce destin transracial

\footnotetext{
${ }^{6}$ Um homem tenro do Quebec, / um dia de verão/ em uma floresta natal/ murmurou: eu sou um abeto. Eu, longe de Jacmel. Uma noite de inverno, / eu sussurrei: eu sou um coqueiro. / O mundo inteiro em nós dois reconheceu filhos gêmeos de sua beleza (Tradução Livre).

7 "Memória proustiana": expressão que faz referência a uma célebre cena do romance À la recherche du temps perdu, de Marcel Proust. Nessa cena, ao comer uma madeleine com chá, o narrador e personagem principal experimenta uma súbita recuperação de sua memória, sendo projetado vivamente em direção ao passado. É, portanto, a partir da memória sensível que são ativadas suas reminiscências mais profundas. Assim funciona também com René Depestre, cuja memória do país natal está mais baseada em elementos materiais da existência do que nos jogos e esforços da inteligência (Tradução Livre).
} 
Où je découvre le seul jour férié du sang ${ }^{8}$

(DEPESTRE, 1980, p. 54).

Ao racial e ao nacional, categorias baseadas na racionalidade, que fundam a cizânia entre os homens, opõe-se o sensível, solução que o poeta encontra para forjar uma identificação que permita universalizar-se. O que se vê então na poesia de Depestre é o que se pode chamar de um sensacionismo universalista no plano da expressão, ao qual se mistura um forte desejo de união no plano político e social, isto é, no plano do conteúdo. O que há, no fundo, é a ideologia da crioulização (esta palavra aqui está entendida no sentido de mistura entre raças e culturas, e não no sentido lingüístico, pois Depestre não escrevia em crioulo), da mestiçagem e da transculturação em atividade. Observa-se isso claramente quando se tem em mente suas palavras em Bonjour et adieu à la Négritude:

Para se libertar do pesadelo racial que tanto marcou e deformou a história do terceiro mundo, seria preciso adquirir novas formas de sentir, de pensar, de sonhar e de agir, no caminho complexo que permite a todo povo livre "subir alto no céu e largo no espaço" da vida em sociedade. A prova está feita: a diversidade dos traços físicos, das nuances de pele, $o$ fato de ser de uma ou de outra cor, devem poder ser vividos como diferenças felizes de uma mesma condição humana (DEPESTRE, 1980, p. 39).

\section{Destino: revolução}

Revolução é uma das palavras que podem ser escritas com maiúsculo quando se fala da poesia de René Depestre, tal é a recorrência do termo através de suas páginas. É uma das palavras que possivelmente agradariam ao poeta se escrita em seu túmulo. Podemos comprovar isso por meio deste Épitaphe:

\section{Dans ta vie tout un jour de pluie}

ne fut jamais plus frais et plus pur

qu'un soir brûlant de révolution

et l'arbre qui passait son temps

\footnotetext{
${ }^{8}$ Profissão de fé transracial/ Os templos os partidos as utopias as razões/ de Estado cessaram para sempre de me emocionar./ No quarto toque será exatamente/ meia noite no quadrante luminoso de meus sonhos./ Onde está a estação que prometia a este mundo árvores de esperança de frescor e de beleza?/ No quarto quadrante eu colocarei todos os meus ismos/ para o momento de um encontro no coração de mim mesmo/ Em que nenhum ser é uma ilha na água de minha ternura./ Minha volta do céu é esse destino transracial/ Onde eu descubro o único dia feriado do sangue (Tradução Livre).
}

\section{à jouer aux échecs avec des nuages fut tout aussi militant qu'un guérillero. ${ }^{9}$}

Pode-se perceber pelo poema que o descanso não é o desejado pelo poeta, preferindo, a um dia de chuva, uma noite quente de revolução, mas sabendo ao mesmo tempo considerar a importância da natureza, considerando-a revolucionária em sua calma. Essa consciência revolucionária do poeta pode ser creditada à história do Haiti.

O país - conhecido na época como Santo Domingo - inicia, em 1791, uma rebelião maciça, e mergulha então no completo caos, fruto da radicalização dos escravos negros da ilha ${ }^{10}$. Depois de várias reviravoltas, que envolveram inclusive os ingleses e os espanhóis, e que intensificaram a situação, Toussaint l'Ouverture, o líder dos negros, assume o controle da situação, mas logo após sucumbe à força expedicionária enviada por Napoleão para recuperar o controle da ilha. O general morre então na França, na prisão, e mais tarde sobe ao comando Dessalines, que consegue derrotar os franceses e proclama a independência do país em 1804. Depois do assassinato de Dessalines, o país passa a ter dois governantes: Henry Cristophe e Alexandre Pétion, o primeiro no norte e o segundo no sul. A situação, no entanto, não era nada boa. Como diz o historiador latino-americano José del Pozo:

Os prejuízos causados pela guerra tinham deixado a economia em frangalhos e o país estava isolado diplomaticamente. A França reconheceu a independência só em 1824, exigindo o pagamento de uma

\footnotetext{
${ }^{9} \mathrm{Em}$ sua vida um dia todo de chuva/ não foi nunca mais fresco e mais puro/ que um anoitecer escaldante de revolução/ e a árvore que passava seu tempo/ jogando xadrez com as nuvens/ foi tão militante quanto um guerrilheiro (Tradução Livre).

${ }^{10}$ Ver, a esse respeito, o excelente estudo Los jacobinos negros, de Cyril Lionel Robert James. É traçado, no livro, um panorama completo da Revolução Haitiana, desde seus antecedentes até as conseqüências que teve no momento imediatamente posterior, tanto para a ilha quanto para as potências envolvidas com ela. A respeito da importância dessa revolução, pode-se ter uma dimensão disso segundo o que dizem os autores, no prefácio à primeira edição: "... dos años después de la Revolución Francesa, los esclavos se rebelaron en Saint-Domingue. La lucha duró doce años. Los esclavos derrotaron, consecutivamente, a los blancos locales y a los soldados de la monarquia francesa, una invasión española, una expedición británica de sesenta mil hombres y una expedición francesa de similar fuerza bajo el mando del cuñado de Bonaparte. La derrota de la expedición de Bonaparte, en 1803, trajo por resultado el establecimiento del Estado negro de Haití, que aún perdura. Esa sublevación es la única revuelta de esclavos exitosa en la historia, y los obstáculos que tuvo que vencer evidencian la magnitud de los intereses involucrados. La transformación de esclavos trêmulos, en grupos de cientos ante un solo hombre blanco, en personas capaces de organizarse y derrotar a la más poderosas de las naciones europeas de la época, es una de las épicas más grandes de la lucha revolucionaria y uno de sus mayores logros" (JAMES, 2013, p. 35-36).
} 
enorme quantia em dinheiro para ressarcir os plantadores brancos pela perda de suas propriedades, e os Estados Unidos ignoraram o novo país por muito tempo. A nova república nascera sob maus agouros (POZO, 2009, p. 25).

O Haiti foi a primeira colônia a se libertar do jugo imperial. Isso, no entanto, não lhe garantiu melhor sorte, como se pode ver pelo trecho acima. O embargo econômico que lhe foi imposto condenou o povo a dois séculos de miséria, até chegar à situação atual. Entre o infortúnio do início da independência até hoje, no entanto, muito chão correu e é nesse meio que se situa Depestre. Crescendo em Jacmel, em meio à pobreza, o poeta não pode deixar de prestar atenção ao que sucedia ao seu redor. Cedo, como foi dito mais acima, engajou-se socialmente e, também, artisticamente, colocando sua poesia a serviço da revolução. Depois do exílio, que o força andar de um lado para o outro, o poeta chega a Cuba, onde trava contato com a revolução que ali se iniciava. Conheceu Che Guevara e Fidel Castro, tornando-se um grande admirador do primeiro. Exemplo disso é dado neste poema.

\section{L'étoile du Che}

Le feu qui a éteint le Che

n'a pas jouit longtemps

de son forfait bolivien

Feu de désolation

Feu de la grande putain

Feu sans aucun des prestiges du feu.

Feu sans aucune des vertus

et des legendes du feu

L'étoile du Che

ne laisse à son horreur

nul espace où briller.

Dans les rêves les plus vastes

dans les plus humbles racines

le Che navigue librement

son étoile protege les récoltes

et défend les miracles des fleurs

en grand vainqueur de sés cendres ${ }^{11}$

(DEPESTRE, 1980, p. 68).

\footnotetext{
11 "O fogo que apagou o Che/ não gozou muito tempo/ seu crime boliviano/ Fogo de desolação/ Fogo da grande puta/ Fogo sem nenhum dos prestígios do fogo. / Fogo sem nenhuma das virtudes/ e das lendas do fogo/ A estrela do Che/ não deixa ao seu horror/ espaço nenhum onde brilhar./ Nos sonhos mais vastos/ nas mais humildes raízes/ o Che navega livremente/ sua estrela protege as colheitas/ e defende os milagres das flores/ em grande vencedor de suas cinzas" (Tradução Livre).
}

O cosmopolitismo de Depestre, ocasionado pelo seu exílio, é bastante presente em seus poemas, incluso os de teor revolucionário. Estes últimos estavam de início embebidos em marxismo, o qual não se apaga mesmo depois do autor se desiludir com a experiência cubana, mas mudam de teor conforme a idade passa. Como se viu no capítulo anterior, ele diz, em um dos poemas analisados aqui, que "Os templos os partidos as utopias e as razões de Estado cessaram para sempre de emocioná-lo.” A admiração a Marx, no entanto, não é menor, como se pode comprovar por meio do poema "Karl Marx":

J'ai foi dans ton étoile

Karl Marx. Tu es resté

tout neuf et propre

sur le mur de mon exil.

Tu voyages aussi la nuit dans les os de ma prose. Tu me regardes fixement en père de mes jardins:

Dans mes yeux tu ne vois pas um éclat de conquinerie.

Tu avives ma tendresse

en soufflant sans cesse

sur sés charbons ardents ${ }^{12}$

(DEPESTRE, 1980, p. 68).

O fim do Estado-nação e uma humanidade transracial são portanto alguns dos ideais do poeta de agora em diante. Sua memória, no entanto, continua plena das coisas que viu pelos lugares onde andou. Pode-se constatar isso em observando o primeiro poema da parte terceira do livro, "D'un exil à l'autre". O poema se chama "Une moitié d'île en dérive", do qual abaixo está transcrito um trecho apenas, dado sua dimensão:

"Jacques a eu les yeux crevés avant un plongeon de mille mètres dans les eaux de la Caraïbe. Jean-Jacques a été enferme avec sa famme Lucette dans la malle d'un chevrolet de l'année 57.

\footnotetext{
${ }^{12}$ Eu tenho fé na tua estrela/ Karl Marx. Tu permaneceste/ bem novo e limpo/ sobre o muro de meu exílio/ Tu viajas também à noite/ dentro dos ossos de minha prosa./ Tu me olhas fixamente/ como pai de meus jardins:/ Nos meus olhos tu não vês/ um brilho de canalhice./ Tu avivas meu carinho/ soprando sem cessar/ sobre seus carvões ardentes (Tradução Livre).
} 
Gérald a eu les poumons en miettes

Raymond a reçu six balles à chaque oeil

Daniel est parti sans couilles

et avec neuf doigts de moins.

Olga, Niclerc, Charles, Arnold, Max

ont été sciés vivants entre deux planches" 13

(DEPESTRE, 1980, p. 45).

Como permanecer com a identidade intacta, quando todos aqueles que se conhece e com os quais se partilha um ideal comum morrem tão brutalmente? Quando aos laços rompidos com os lugares juntam-se os laços (também forçosamente) rompidos com as pessoas? A causa revolucionária a favor da qual se engaja o poeta é, como se pôde perceber, desde o início o fator diaspórico em sua jornada, ocasionando os sucessivos rompimentos e impulsionando o crescimento de uma personalidade à deriva e constantemente em mutação, um amálgama de tudo aquilo e todos aqueles que desfilaram ante os seus olhos.

\section{Considerações finais}

Uma das alternativas de pessoas que vivem em país onde há guerras civis, perseguições políticas, religiosas ou de qualquer outro tipo é exilar-se, desenraizar-se e partir para novos rumos, com os quais geralmente não se possui nenhum vínculo. Essa foi a alternativa seguida pelo poeta do qual falamos durante este artigo. René Depestre deixa sua terra natal ainda muito cedo e permanece em um destino errante, mudando de país em país, seguindo sempre suas convicções ideológicas. A partir de 1980 ele se estabelece em Lézignan-Corbières, pequena comunidade francesa, mas até esse ano sua vida foi um constante passar entre terras distintas.

Esse estabelecimento, contudo, não apaga e nem destrói os laços que o poeta manteve com sua cidade natal e com seu país de uma maneira geral. Vimos, seguindo as considerações de Stuart Hall, que essa é uma condição das pessoas que passam por esse tipo de migração: permanecem sempre com o pé cha-

\footnotetext{
${ }^{13}$ Jacques teve os olhos furados/ antes de um mergulho de mil metros/ nas águas do Caribe/ Jean-Jacques foi trancado/ com sua mulher Lucette no porta-malas/ de um Chevrolet ano 57./ Gérald teve os pulmões em pedacinhos/ Raymond recebeu seis balas em cada olho/ Adrian teve a barriga perfurada/ Gladys teve os seios despedaçados/ Daniel partiu sem saco/e com nove dedos a menos./ Olga, Niclerc, Charles, Arnold, Max/ foram serrados vivos entre duas pranchas (Tradução Livre).
}

mado memória no lugar onde nasceram, no lugar em que aprenderam a ler o mundo. Na poesia de Depestre isso é bastante marcado, principalmente no que diz respeito ao seu contato com a exuberância da natureza caribenha. O poeta, no entanto, sempre esteve atento para a pobreza humana que circulava na ilha.

Essa pobreza despertou muito cedo seu senso revolucionário, fazendo-o engajar a si e sua arte a favor da revolução. Essa arte, no entanto, não é panfletária, não quer alardear nem fazer propaganda. É nascida, antes de mais nada, de um homem que deseja estar em comunhão com os seus semelhantes e acredita na poesia como uma das maneiras de fazê-lo.

Espera-se que este pequeno artigo tenha contribuído para um melhor conhecimento do poeta, cuja poesia é sofrivelmente difundida em língua portuguesa, dando a conhecer, assim, uma pequena parcela de sua arte, por meio da qual podem ser abordadas estas e outras tantas questões que permeiam a vida dos homens.

\section{Referências}

DEPESTRE, René. En état de poésie. Paris: Les éditeurs français réunis, 1980.

DEPESTRE, René. Rage de vivre: oeuvres poétiques completes. Paris: Seghers, 2006.

FIGUEIREDO, Eurídice. Representações de etnicidade: perspectivas interamericanas de literatura e cultura. Rio de Janeiro: Viveiros de Castro Editora Ltda, 2010.

HALL, Stuart. Da diáspora: Identidades e mediações culturais. Org. de Liv Sovik. Tradução de Adelaide La Guardia Resende ... [et al.]. Belo Horizonte: Editora UFGM, 2013.

JAMES, Cyril Lionel Robert. Los jacobinos negros: Toussaint L'Ouverture y la Revolución de Haití. Tradución de Rosa López Oceguera. Buenos Aires: RyR, 2013.

PIZZARO, Ana. O sul e os trópicos: ensaios de cultura latino-americana. Niterói: Editora da Universidade Federal Fluminense, 2010.

POZO, José del. História da América Latina e do Caribe: Dos processos de Independência aos dias atuais. Tradução de Ricardo Rosenbusch. Petrópolis: Vozes, 2009.

Recebido em: 29-07-2015

Aceito em: 16-11-2015 